\title{
Long-term behavior of aortic intramural hematomas and penetrating ulcers
}

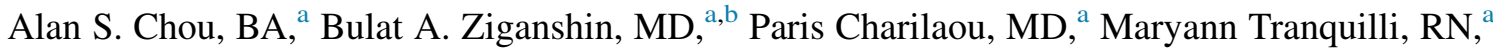 \\ John A. Rizzo, PhD, ${ }^{\mathrm{a}, \mathrm{c}}$ and John A. Elefteriades, $\mathrm{MD}^{\mathrm{a}}$
}

\section{ABSTRACT}

Objective: For intramural hematoma and penetrating atherosclerotic ulcer, long-term behavior and treatment are controversial. This study evaluates the long-term behavior of intramural hematoma and penetrating atherosclerotic ulcer, including radiologic follow-up and survival analysis.

Methods: Between 1995 and 2014, 108 patients (mean age, $70.8 \pm 10$ years; $56 \%$ female) presented with intramural hematoma or penetrating atherosclerotic ulcer to Yale-New Haven Hospital (New Haven, Conn). We reviewed the medical records, radiology, and online mortality databases.

Results: Ten of 55 patients $(18 \%)$ with intramural hematoma and 17 of 53 patients $(32 \%)$ with penetrating atherosclerotic ulcer had rupture state symptoms on admission, both greater than type A $(8 \%)$ or type B dissection $(4 \%)(P<.001)$. No branch vascular occlusion occurred. For patients with intramural hematoma with follow-up imaging, 8 of 14 (57\%) worsened (mean follow-up, 9.4 months) and $6(43 \%)$ underwent late surgery. For patients with penetrating atherosclerotic ulcer with follow-up imaging, 6 of $20(30 \%)$ worsened and underwent late surgery, and $11(55 \%)$ showed no change (mean follow-up, 34.3 months). Overall survivals were $77 \%, 70 \%, 58 \%$, and $33 \%$ at $1,3,5$, and 10 years, respectively. No operative deaths occurred for patients with nonrupture state. Patients with penetrating atherosclerotic ulcer with initial surgical treatment had better long-term survival than patients treated medically $(P=.037)$. In the intramural hematoma group, no such difference was observed $(P=.10)$.

Conclusions: At presentation, the incidence of early rupture of intramural hematoma and penetrating atherosclerotic ulcer was higher than for typical dissection. For branch vessels, intramural hematoma never occludes branch arteries. On imaging follow-up, patients with intramural hematoma and penetrating atherosclerotic ulcer rarely improved, with late surgery commonly needed. Better survival was observed for the initial surgical management of patients with penetrating atherosclerotic ulcer compared with initial medical management. (J Thorac Cardiovasc Surg 2016;151:361-73)

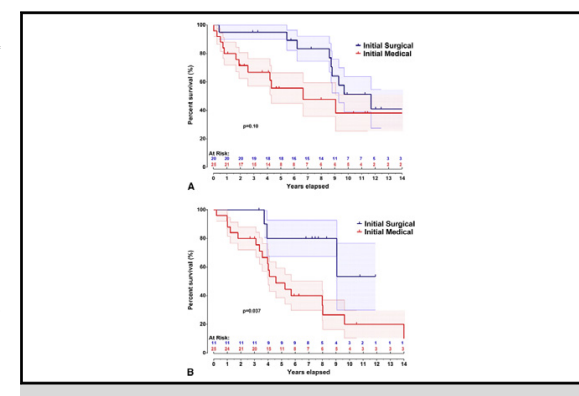

Kaplan-Meier survivals comparing treatment of patients with nonrupture state. A, IMH. B, PAU.

\section{Central Message}

IMH and PAU lesions rarely resolve, and surgery effectively restores survival. A more aggressive approach may be warranted.

\section{Perspective}

The long-term behavior and treatment of IMH and PAU are controversial. On the basis of substantial rates of worsening and late surgery, low operative mortality, and improvements in actuarial survival, we advocate a more aggressive surgical approach to these lesions. For experienced clinicians, the threshold toward surgical intervention should be lowered as evidence suggests that surgery is safe and effective.

See Editorial Commentary page 374.

See Editorial page 294.

\footnotetext{
From the a Aortic Institute at Yale-New Haven Hospital, Yale University School of Medicine, New Haven, Conn; ${ }^{b}$ Department of Surgical Diseases \#2, Kazan State Medical University, Kazan, Russia; and ${ }^{\mathrm{c}}$ Department of Economics and Department of Preventive Medicine, Stony Brook University, Stony Brook, New York, NY.

Read at the 95th Annual Meeting of The American Association for Thoracic Surgery, Seattle, Washington, April 25-29, 2015.

Received for publication April 27, 2015; revisions received Aug 22, 2015; accepted for publication Sept 3, 2015; available ahead of print Oct 20, 2015.

Address for reprints: John A. Elefteriades, MD, Aortic Institute at Yale-New Haven Hospital, Yale University School of Medicine, 789 Howard Ave, Clinic Building CB317, New Haven, CT 06510 (E-mail: john.elefteriades@yale.edu). $0022-5223 / \$ 36.00$

Copyright (c) 2016 by The American Association for Thoracic Surgery http://dx.doi.org/10.1016/j.jtcvs.2015.09.012
} 


\section{Abbreviations and Acronyms \\ CT = computed tomography \\ ILVA $=$ isolated left vertebral artery \\ IMH = intramural hematoma \\ MRI = magnetic resonance imaging \\ PAU = penetrating atherosclerotic ulcer \\ TEVAR $=$ thoracic endovascular aortic repair}

contained within the aortic wall. Penetrating ulcers are characterized by interruption of the intima of the aortic wall, with penetration into the media, whereas IMHs are characterized by hematoma contained within the aortic wall. $^{2,3}$

IMH and PAU are typically diagnosed via computed tomography (CT) or magnetic resonance imaging (MRI). ${ }^{4}$ IMH is thought to represent a rupture of the vasa vasorum into the media that results in a crescentic thickening of the aortic wall; it is differentiated from classic dissection by an intact intima that precludes flow communication., ${ }^{2,3}$ Penetrating ulcers, as described by Cho and colleagues, ${ }^{5}$ are characterized as ulcerations (commonly in an atheromatous plaque) involving intimal and partial medial disruption and possible formation of a hematoma surrounding the projection.

Both IMH and PAU are known to have complex, varied courses. It is well known that these lesions can resolve spontaneously, remain stable, or progress to aneurysm, classic dissection, or rupture. ${ }^{6}$ Despite an increasing amount of literature reports, debate persists regarding the course and optimal treatment of IMH and PAU, summarized in Table 1..$^{3,4,16,17}$ Supporters of initial nonsurgical treatment cite data indicating that IMHs resolve readily and do not require aggressive surgical treatment, even when located in the ascending aorta. ${ }^{7,8,10,12-14,18}$ However, conflicting results, including a prior study from this center, point to infrequent healing and a subsequent need for surgical repair. ${ }^{6,11,19}$ Likewise, some retrospective studies on PAU demonstrate low rates of worsening and adverse events over time, permitting nonsurgical treatment, whereas other studies find high rates of radiographic progression, encouraging a lower threshold for early surgical repair. ${ }^{5,6,15}$ These conflicting data are further complicated by a paucity of long-term follow-up of IMHs and PAUs.

In a previous report, we presented midterm follow-up results. ${ }^{6}$ We extend this follow-up with an aim at elucidating the long-term natural history and progression of IMHs and penetrating ulcers. We focus on lesion progression and subsequent management, providing both presurgical and postsurgical follow-up with the intent to inform decision-making regarding these acute aortic syndromes.

\section{MATERIALS AND METHODS Patient Profile}

From the Yale Aortic Institute database of patients (New Haven, Conn) with acute aortic syndromes, we identified a total of 108 patients with IMH $(\mathrm{n}=55)$ and PAU $(\mathrm{n}=53)$. All presented acutely (with chest pain and syncope) and were treated at Yale-New Haven Hospital (New Haven, Conn) between June 1995 and February 2014. Records for the study population were retrospectively reviewed and consisted of chart and electronic medical records, imaging records, telephone call follow-up, and Social Security Death Index mortality analysis.

We examined symptoms at initial presentation, demographic data, comorbidities, hospital course, treatment, interventions (if any), in-hospital mortality, late mortality, and other pertinent clinical follow-up. Radiologic analysis included review of angiogram, CT, and MRI and records for characterization of initial pathologic entity and subsequent radiographic course, both before and after intervention, to determine disease progression. Patient mortality was determined via hospital records and Social Security Death Index. Hospital discharge summaries and state death certificates were used to ascertain causes of death when possible. Follow-up was $100 \%$ complete. The study was approved by the Institutional Review Board of Yale University.

\section{Long-term Radiology Follow-up Guidelines}

Clinical and radiologic criteria were used to characterize lesions as follows:

- Patients were classified by their initial diagnosis (IMH or PAU) on earliest available imaging. If transition to another lesion type or to typical dissection occurs in later follow-up, this progression is recorded, but the original diagnosis is maintained for analysis.

- IMH is characterized by crescentic or circular shadowing and expansion within the aortic wall and is differentiated from dissection by the lack of an intimal flap. IMH is confirmed by contrast and noncontrast CT or MRI, when available, to demonstrate lack of flow communication. Patients with an ascending IMH that extended through the arch or descending aorta were considered as part of the ascending cohort. ${ }^{20}$

- Penetrating ulcers are identified as contract opacified projections into the medial wall, often with a mushroom-like appearance. PAUs surrounded by localized IMH were classified as PAU, reflecting our view that it is more likely that the PAU resulted in the located hematoma, rather than the alternative. In cases difficult to classify, the senior author directly reviewed the images to optimize classification. ${ }^{20}$

- Rupture state indicates rupture or impending rupture symptoms. Rupture was determined by the presence of extra-aortic blood confirmed by radiology, surgical examination, or postmortem examination; impending rupture was determined largely on the basis of radiologic findings (bloody or increasing pleural effusion, severe radiologic worsening of the aortic contour), clinical behavior (persistent pain, despite medical treatment), or intraoperative findings of impending rupture (periaortic hematoma without frank rupture, extreme wall thinning).

Progression of our observed pathologies was classified into 3 groups as follows (Figure 1):

- Decrease in size or disappearance of hematoma or ulcer was recorded as "resolution."

- "Worsening" refers to deterioration in aortic condition, including significant increases in the thickness or depth of the lesion, progression of PAU to IMH (or vice versa), progression to classic dissection, or rupture.

- Patients whose lesions did not improve or worsen significantly were noted to be "stable."

We also examined postsurgical imaging findings of repaired aortas. Notations and imaging evidence of aortic instability, including formation of aneurysm, pseudoaneurysm, dissection, endoleak, or contrast 
TABLE 1. Findings and recommendations for intramural hematoma and penetrating atherosclerotic ulcer follow-up studies

\begin{tabular}{|c|c|c|c|c|}
\hline Author & Institution and date & Lesion & Findings & Treatment recommendation \\
\hline Tittle and colleagues ${ }^{6}$ & Yale, 2002 & $\begin{array}{r}\text { IMH, type } \\
\mathrm{A} \text { and } \mathrm{B}\end{array}$ & $\begin{array}{l}\text { "high rates of rupture on presentation, the frequency } \\
\text { of worsening on follow-up, and continued incidence } \\
\text { of death from rupture... Lesions to be preferentially } \\
\text { surgically treated" }\end{array}$ & Expanded surgical treatment \\
\hline $\begin{array}{r}\text { Moizumi and } \\
\text { colleagues }^{7}\end{array}$ & $\begin{array}{l}\text { Tohuku University, } \\
2004\end{array}$ & $\begin{array}{l}\text { IMH, type } \\
\text { A and B }\end{array}$ & $\begin{array}{l}\text { "Our results do not necessarily support [Tittle's] } \\
\text { recommendations... } 50 \% \text { of patients with type A } \\
\text { IMH and } 70 \% \text { of patients with type B IMH can be } \\
\text { managed medically alone" }\end{array}$ & $\begin{array}{l}\text { Initial medical treatment } \\
\text { with expectant surgery }\end{array}$ \\
\hline Kaji and colleagues $^{8}$ & $\begin{array}{c}\text { Kobe City General } \\
\text { Hospital, } 2003\end{array}$ & IMH, type B & $\begin{array}{l}\text { "Considering both low in-hospital mortality and good } \\
\text { long-term prognosis, ... supportive medical therapy } \\
\text { and timed surgical repair may be a reasonable option" }\end{array}$ & $\begin{array}{l}\text { Initial medical treatment } \\
\text { with expectant surgery }\end{array}$ \\
\hline $\begin{array}{l}\text { Evangelista and } \\
\text { colleagues }^{9}\end{array}$ & IRAD, 2005 & IMH, type A & $\begin{array}{l}\text { "The mortality of acute IMH involving the ascending } \\
\text { aorta remains high... [we] continue to favor } \\
\text { consideration for timely surgical approach..." }\end{array}$ & Initial surgical treatment \\
\hline $\begin{array}{l}\text { Evangelista and } \\
\text { colleagues }^{9}\end{array}$ & IRAD, 2005 & IMH, type B & $\begin{array}{l}\text { "acute IMH involving the descending aorta had an } \\
\text { in-hospital risk of }<10 \% \ldots \text { Initial medical treatment } \\
\text { for this condition appears justified" }\end{array}$ & $\begin{array}{l}\text { Initial medical treatment } \\
\text { with expectant surgery }\end{array}$ \\
\hline Kitai and colleagues ${ }^{10}$ & $\begin{array}{c}\text { Kobe City General } \\
\text { Hospital, } 2009\end{array}$ & IMH, type A & $\begin{array}{l}\text { "Medical therapy with or without timely operation } \\
\text { resulted in favorable long-term results... Prophylactic } \\
\text { emergent surgery may not be always necessary for } \\
\text { patients with type A IMH" }\end{array}$ & $\begin{array}{l}\text { Initial medical treatment } \\
\text { with expectant surgery }\end{array}$ \\
\hline $\begin{array}{l}\text { Shimokawa and } \\
\text { colleagues }^{11}\end{array}$ & $\begin{array}{c}\text { Sakakibara Heart } \\
\text { Institute, } 2008\end{array}$ & IMH, type A & $\begin{array}{l}\text { "immediate surgical treatment... results in lower } \\
\text { mortality rates and acceptable midterm survival and } \\
\text { freedom from IMH-related events" }\end{array}$ & Initial surgical treatment \\
\hline Song and colleagues ${ }^{12}$ & $\begin{array}{l}\text { Asan Medical } \\
\text { Center, } 2009\end{array}$ & IMH, type A & $\begin{array}{l}\text { “...initial medical treatment for stable patients with } \\
\text { surgery for complications showed acceptable } \\
\text { outcomes.” }\end{array}$ & $\begin{array}{l}\text { Initial medical treatment } \\
\text { with expectant surgery }\end{array}$ \\
\hline Sawaki and colleagues ${ }^{13}$ & $\begin{array}{c}\text { Nagoya Ekisaikai } \\
\text { Hospital, } 2010\end{array}$ & IMH, type A & $\begin{array}{l}\text { "Even in high-risk cases, the outcome of medical } \\
\text { treatment for type A IMH during the acute period } \\
\text { was fairly good." }\end{array}$ & $\begin{array}{l}\text { Initial medical treatment } \\
\text { with expectant surgery }\end{array}$ \\
\hline $\begin{array}{l}\text { Tolenaar and } \\
\text { colleagues }^{14}\end{array}$ & IRAD, 2013 & IMH, type B & $\begin{array}{l}\text { "Most IMH B patients have a more limited extent } \\
\text { of disease and can be treated medically... a } \\
\text { complication specific approach can be adopted" }\end{array}$ & $\begin{array}{l}\text { Initial medical treatment } \\
\text { with expectant surgery }\end{array}$ \\
\hline Tittle and colleagues ${ }^{6}$ & Yale, 2002 & PAU & $\begin{array}{l}\text { "high rates of rupture on presentation, the frequency } \\
\text { of worsening on follow-up, and continued incidence } \\
\text { of death from rupture... Lesions to be preferentially } \\
\text { surgically treated" }\end{array}$ & $\begin{array}{l}\text { Expanded surgical } \\
\text { treatment }\end{array}$ \\
\hline Cho and colleagues ${ }^{5}$ & Mayo Clinic, 2004 & PAU & $\begin{array}{l}\text { "Our recommendations are at variance with... Tittle. } \\
\text { We advocate a more expectant approach. }\end{array}$ & $\begin{array}{l}\text { Initial medical treatment } \\
\text { with expectant surgery }\end{array}$ \\
\hline Nathan and colleagues ${ }^{15}$ & $\begin{array}{l}\text { University of } \\
\text { Pennsylvania, } 2012\end{array}$ & PAU & $\begin{array}{l}\text { "36\% of symptomatic PAUs eventually required } \\
\text { repair, and } 43 \% \text { of symptomatic PAUs had } \\
\text { radiographic progression" }\end{array}$ & None \\
\hline
\end{tabular}

$\overline{I M H}$, Intramural hematoma; IRAD, International Registry of Acute Aortic Dissection; PAU, penetrating atherosclerotic ulcer. *Bolded text highlights contrasting treatment recommendations.

extravasation, were noted as "postsurgical aortic complications." Aortas with no postoperative signs of progression were noted as "stable." All imaging findings were correlated with radiology reports, consult letters, and operative reports when available.

\section{General Management Strategy}

Our general policy toward treatment was expectant but aggressive. We operated on all patients in rupture state and all ascending lesions when clinically possible. For descending IMH and PAU, we provided standard initial nonsurgical anti-impulse therapy, yet maintained a low threshold for surgical intervention in case of severe, recurrent symptoms or radiographic worsening on follow-up. Our policy originated in the pre-endovascular era, and the majority of our operatively treated patients underwent open repair rather than endovascular treatment. Patients whose age or comorbidities made them poor operative candidates were excluded from this management policy.

\section{Statistical Analysis}

Data are reported as mean \pm standard deviation or as percentages. Comparison of means is performed via Student $t$ test; comparison of proportions is performed via Pearson's chi-square test. ${ }^{21}$ Survival curves are performed via the Kaplan-Meier method with statistical differences 

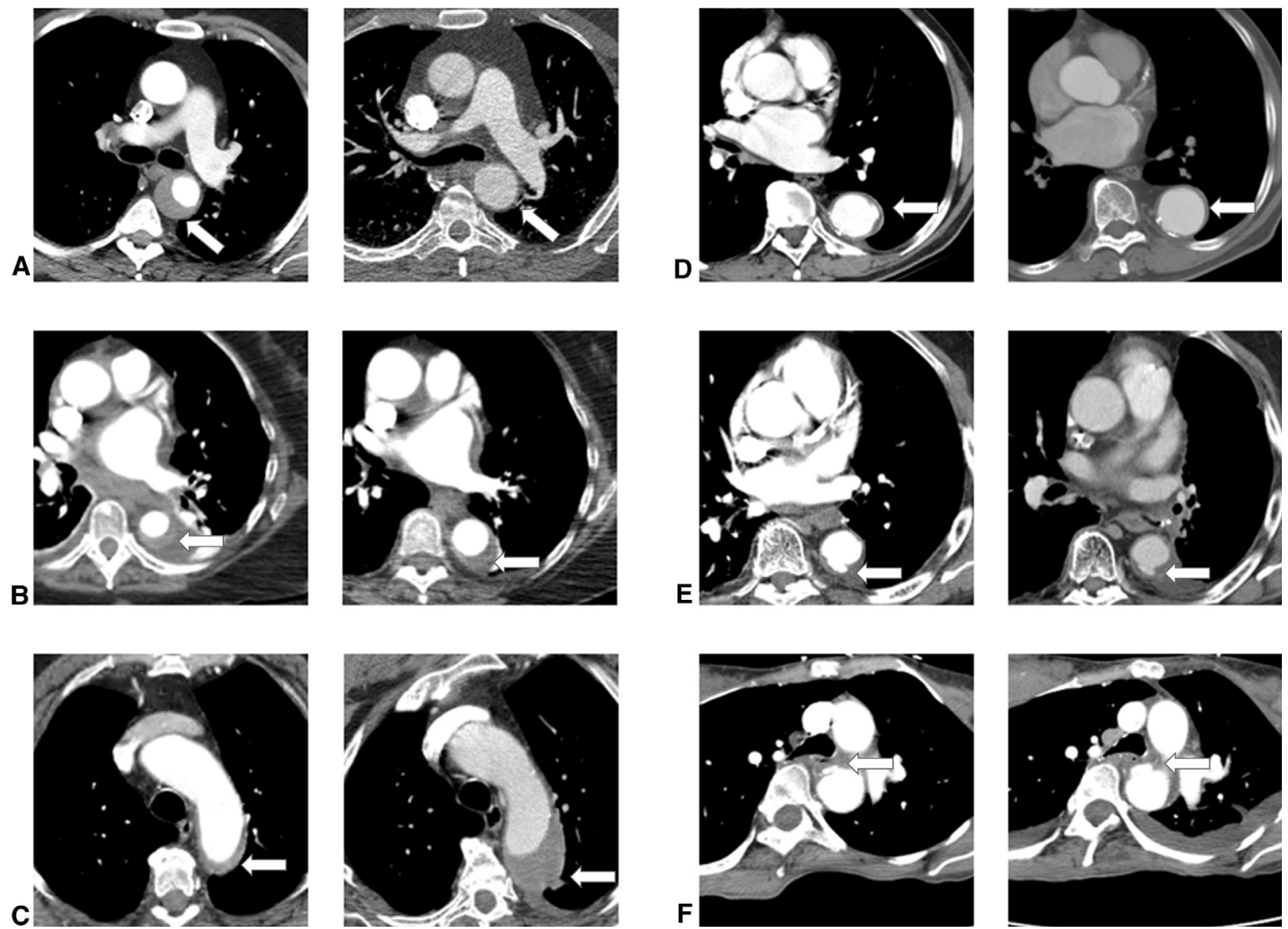

FIGURE 1. Sample radiographic (CT) images demonstrating possible outcomes of imaging follow-up. Left images demonstrate initial state; right images demonstrate progression on follow-up White arrows indicate the site of the lesions. For IMH: resolution (A); unchanged (B); worsening (rapid expansion) (C). For PAU: resolution (D); unchanged (E); worsening (rapid expansion) (F).

assessed for significance by the Mantel-Cox and Gehan-Wilcoxon (larger weight on early deaths) log-rank tests, selected a priori; median survival indicates the earliest time point for which survival decreases to less than $50 \%$. Statistical comparisons with classic dissection patients uses data from past studies performed at the Yale Aortic Institute (New Haven Conn) and data collected by the International Registry of Acute Aortic Dissection. ${ }^{1,22}$ Calculations were performed using Microsoft Excel (Microsoft Corp, Redmond, Wash), MATLAB (MathWorks Inc, Natick, Mass), and GraphPad Prism (GraphPad Software Inc, La Jolla, Calif).

\section{RESULTS}

\section{Overall Behavior of Lesions}

In total, 108 patients with acute aortic dissections were examined (Table 2). All patients presented acutely and were symptomatic. The mean age at diagnosis for patients with IMH and PAU was significantly greater when compared with the mean age of classic aortic dissection, $63.1 \pm 14$ years $(P<.001) .{ }^{1}$ In addition, IMH and PAU both occurred more frequently in female patients $(56 \%)$ than male patients, again significantly different than the classic dissection, in which only $35 \%$ of patients were female $(P<.001)$. The majority of both lesions occurred in the descending aorta. No significant differences were observed for the prevalence of comorbidities in Table 2 between the IMH and PAU cohorts or between the ascending and descending cohorts. Two patients in the overall cohort had confirmed Marfan syndrome, 1 in each of the IMH and PAU groups, both with lesions in the descending aorta. For patients with IMH, no branch vascular occlusion was noted for any patients in this study.

The prevalence of atypical aortic branching variants was significantly elevated in this cohort. In the overall cohort, the prevalence of some atypical aortic branching variants, including bovine aortic arch, isolated left vertebral artery (ILVA), and aberrant right subclavian artery, was $27 \%$, significantly greater compared with the normal prevalence, $18.2 \%$, of atypical aortic branching variants in healthy populations $(P<.05){ }^{23}$ The rate of ILVA was particularly elevated, with an overall prevalence of $12 \%$ compared with a population prevalence of $3.4 \%(P<.005)$. Among patients with descending IMH, atypical prevalence was 
TABLE 2. Comorbidities, hospital course, and outcomes for patients with intramural hematoma or penetrating atherosclerotic ulcer by anatomic location of lesion

\begin{tabular}{|c|c|c|c|c|c|c|c|c|}
\hline \multirow[b]{2}{*}{ Variables } & \multirow[b]{2}{*}{ Total cohort } & \multicolumn{3}{|c|}{ IMH } & \multicolumn{3}{|c|}{ PAU } & \multirow{2}{*}{$\begin{array}{l}P(\text { all IMH } \\
\text { vs all PAU) }\end{array}$} \\
\hline & & All IMH & Ascending & Descending & All PAU & Ascending & Descending & \\
\hline No. of patients & 108 & $55(51 \%)$ & $18(33 \%)$ & $37(67 \%)$ & $53(49 \%)$ & $4(8 \%)$ & $49(92 \%)$ & \\
\hline Mean age at diagnosis (y) & $70.8 \pm 10$ & $70.3 \pm 10$ & $70.4 \pm 10$ & $70.2 \pm 12$ & $71.4 \pm 10$ & $70.3 \pm 14$ & $70.3 \pm 15$ & .94 \\
\hline Female $(\%)$ & $61(56 \%)$ & $31(56 \%)$ & $10(56 \%)$ & $21(57 \%)$ & $30(57 \%)$ & $1(25 \%)$ & $29(59 \%)$ & 1.0 \\
\hline Hypertension & $99(92 \%)$ & $51(93 \%)$ & $15(83 \%)$ & $36(97 \%)$ & $48(91 \%)$ & $4(100 \%)$ & $44(90 \%)$ & .74 \\
\hline Dyslipidemia & $48(44 \%)$ & $21(38 \%)$ & $7(39 \%)$ & $14(38 \%)$ & $27(51 \%)$ & $2(50 \%)$ & $25(51 \%)$ & .25 \\
\hline Tobacco & $35(32 \%)$ & $16(29 \%)$ & $6(33 \%)$ & $10(27 \%)$ & $19(36 \%)$ & $2(50 \%)$ & $17(35 \%)$ & .54 \\
\hline Coronary artery disease & $31(29 \%)$ & $13(26 \%)$ & $3(17 \%)$ & $10(27 \%)$ & $18(34 \%)$ & $2(50 \%)$ & $16(33 \%)$ & .29 \\
\hline Pulmonary disease & $35(32 \%)$ & $14(25 \%)$ & $4(22 \%)$ & $10(27 \%)$ & $21(40 \%)$ & $3(75 \%)$ & $18(37 \%)$ & .15 \\
\hline Renal dysfunction & $13(12 \%)$ & $7(13 \%)$ & $2(11 \%)$ & $5(14 \%)$ & $6(11 \%)$ & $1(25 \%)$ & $5(10 \%)$ & 1.0 \\
\hline Aortic branching variant & $29(27 \%)$ & $17(31 \%)$ & $4(22 \%)$ & $13(35 \%)$ & $12(23 \%)$ & $1(25 \%)$ & $11(22 \%)$ & \\
\hline ILVA & $13(12 \%)$ & $9(16 \%)$ & $1(6 \%)$ & $8(22 \%)$ & $4(8 \%)$ & $1(25 \%)$ & $3(6 \%)$ & \\
\hline Rupture state & $27(25 \%)$ & $10(18 \%)$ & $3(17 \%)$ & $7(19 \%)$ & $17(32 \%)$ & $3(75 \%)$ & $14(29 \%)$ & \\
\hline \multicolumn{9}{|l|}{ Nonrupture state } \\
\hline Initial surgical treatment & $31(29 \%)$ & $20(36 \%)$ & $14(78 \%)$ & $6(16 \%)$ & $11(21 \%)$ & $0(0 \%)$ & $11(22 \%)$ & \\
\hline Initial medical treatment & $50(46 \%)$ & $25(45 \%)$ & $1(6 \%)$ & $24(65 \%)$ & $25(47 \%)$ & $1(25 \%)$ & $24(49 \%)$ & \\
\hline Total nonoperative & $46(43 \%)$ & $22(40 \%)$ & $2(11 \%)$ & $20(54 \%)$ & $24(45 \%)$ & $2(50 \%)$ & $22(45 \%)$ & \\
\hline Total operative & $62(57 \%)$ & $33(60 \%)$ & $16(89 \%)$ & $17(46 \%)$ & $29(55 \%)$ & $2(50 \%)$ & $27(55 \%)$ & \\
\hline Early mortality & $15(14 \%)$ & $8(15 \%)$ & $3(17 \%)$ & $5(14 \%)$ & $7(13 \%)$ & $1(25 \%)$ & $6(12 \%)$ & \\
\hline Median survival (mo) & 95.9 & 105.7 & 111.6 & 79.8 & 62.9 & 76.3 & 55.0 & \\
\hline
\end{tabular}

IMH, Intramural hematoma; $P A U$, penetrating atherosclerotic ulcer; ILVA, isolated left vertebral artery.

$35 \%$, significantly elevated compared with the prevalence in the general population $(P<.05)$, whereas ILVA prevalence was $22 \%$, also significantly above population prevalence $(P<.001)$.

As expected by treatment protocol, rates of initial medical and initial surgical treatment were significantly different for ascending and descending cohorts of both IMH and PAU cohorts, reflecting our treatment bias that ascending lesions are more serious than descending lesions. The rate of initial surgical treatment for ascending IMH $(89 \%)$ was higher compared with descending IMH $(30 \%)$ $(P<.001)$. The frequency of operative repair for patients with IMH, both early and late, was significantly higher for ascending lesions $(89 \%)$ than for descending lesions $(46 \%)(P<.01)$.

\section{Treatment and Course of Intramural Hematoma}

A total of 55 patients with IMH were studied (Figure 2, $A$ ). The average age at diagnosis was 70.9 years (range, $47-88$ years), and 31 patients $(56 \%)$ were female (Figure 3, A). The IMH originated in the ascending aorta in 18 patients $(33 \%)$ and in the descending aorta in 37 patients $(67 \%)$ (Figure 3, B).

Of the 55 patients, 10 presented with rupture state symptoms (rupture or impending rupture), representing an incidence of rupture at presentation of $18 \%$ compared with $8 \%$ and $4 \%$ for type $\mathrm{A}$ and $\mathrm{B}$ classic dissection previously observed $(P<.05)$. Of those 10 patients, 7 $(70 \%)$ were treated surgically, and the other 3 patients $(30 \%)$ were considered inoperable because of age and other major comorbidities. Four patients $(40 \%)$ had impending rupture, and 6 patients $(60 \%)$ had realized rupture. Of the 4 patients with impending rupture, $2(50 \%)$ underwent surgery and survived to discharge, and $2(50 \%)$ did not undergo surgery and did not survive to discharge. Only 1 of the 6 patients with realized rupture $(17 \%)$ survived to discharge after emergency surgery. In total, of patients who presented with rupture state symptoms, none of the 3 nonsurgical patients survived to discharge and 3 surgical patients $(30 \%)$ survived to discharge. On the basis of the severity of symptoms, radiographic images, and comorbidities, the 45 patients $(82 \%)$ with nonrupture state IMH were triaged to initial surgical or initial medical therapy. Twenty patients $(44 \%)$ were triaged to initial surgical repair, and the remaining 25 patients $(56 \%)$ were treated medically, with regular follow-up imaging. Late surgical repair was performed on 6 patients. In total, 33 patients underwent operative repair: 27 with surgical aortic graft replacement (details on the extent of surgical graft replacement are provided in Table E1 in the Appendix), 3 with descending endovascular graft, and 3 with aortic thromboexclusion (in the pre-endograft era). No in-hospital deaths occurred for any patients in nonrupture state. One early death at 10 days occurred in hospice for a medically treated patient who refused recommendations for surgery.

In total, 48 patients ( $87 \%$ ) survived to first discharge, and postdiagnosis follow-up imaging was available for 26 patients $(54 \%)$. Overall mean imaging follow-up time was 31.3 months (range, 1-140). Of the 25 initially 

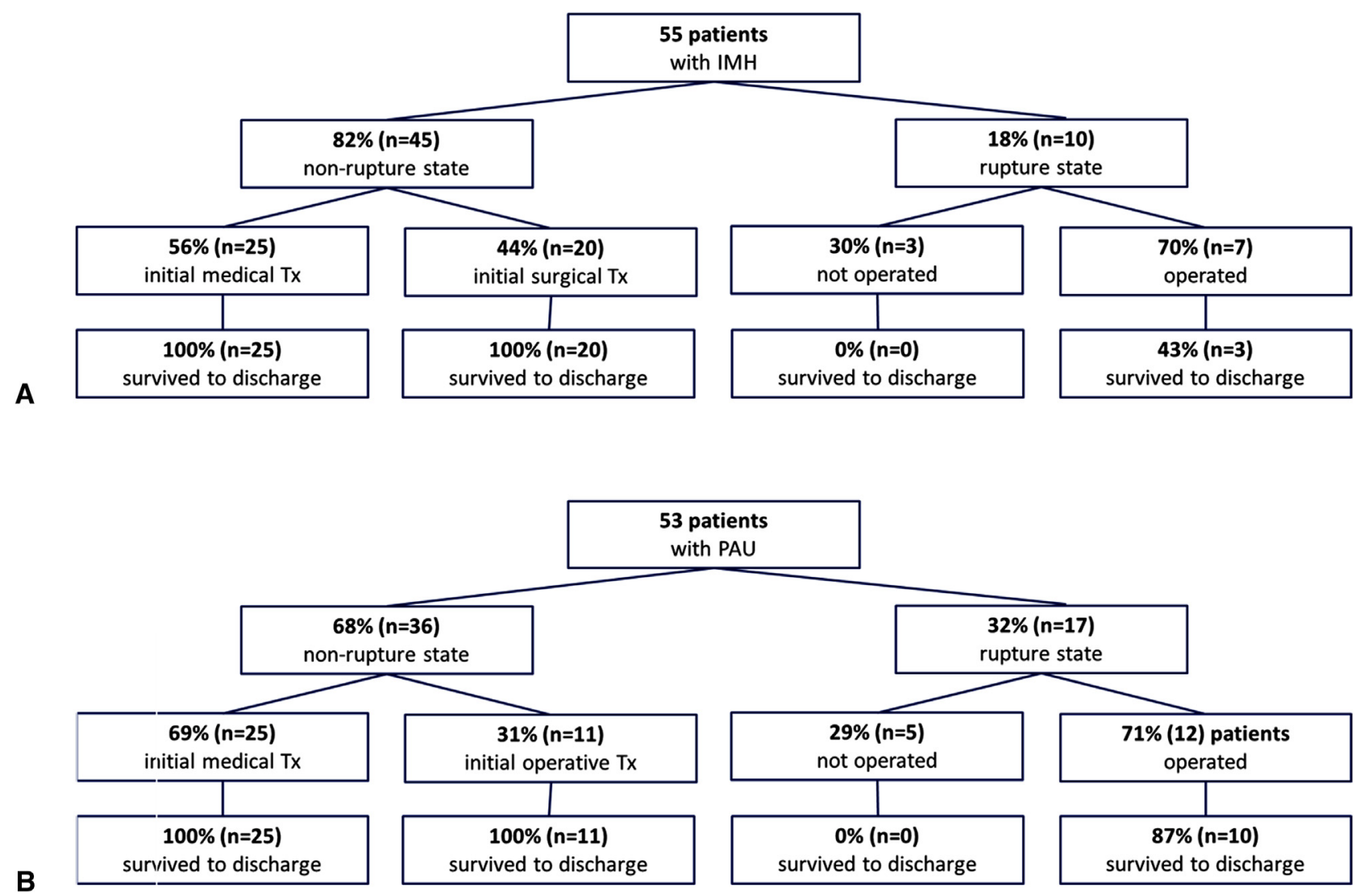

FIGURE 2. Flowchart for hospital course: IMH (A) and PAU (B) patient cohorts. $I M H$, Intramural hematoma; $T x$, treatment; $P A U$, penetrating atherosclerotic ulcer.

medically treated patients, imaging follow-up was available for $14(56 \%)$, with mean imaging time during medical treatment period of 9.4 months (range, 1-54) (Figure 4, A). Four patients $(29 \%)$ demonstrated spontaneous resolution of the IMH lesion (mean imaging time, 23.3 months; range, 3-52), and 2 (14\%) showed no change in appearance (mean imaging time, 3.8 months; range, 2-6). Eight patients $(57 \%)$ showed worsening, with $3(38 \%)$ demonstrating conversion to flap dissection, $3(38 \%)$ manifesting appearance of a concurrent penetrating ulcer, and $2(25 \%)$ manifesting rapid expansion of the IMH. The mean time to detection of worsening was 1.3 months (range, 0.4-2.5). Late operation was performed on 6 of the 8 patients who displayed worsening, with a mean time to late operation of 4.2 months (range, 0.6-19). All patients who underwent late surgery survived to discharge.

A total of 33 patients with IMH had operative repair during their overall treatment course, with $29(88 \%)$ surviving to first discharge. Seventeen patients $(59 \%)$ had postsurgical follow-up imaging, with a mean imaging time of 39.6 months (range, 2-140) (Figure 4, B). Eleven patients $(65 \%)$ demonstrated stable aortic appearance (mean imaging time, 31.2 months; range, 2-140), whereas 6 patients $(35 \%)$ showed postsurgical aortic complications (mean imaging time, 56.7 months; range, 5-104). Two of the 3 patients treated with thromboexclusion demonstrated deterioration, with 1 demonstrating development of type A dissection and 1 demonstrating erosion of aortic clips. Two patients who were repaired with thoracic endovascular aortic repair (TEVAR) demonstrated endoleak, and 2 surgically repaired patients demonstrated pseudoaneurysm or dissection. Four patients (24\%) underwent redo surgery to address long-term postsurgical complications. Total operative mortality for the IMH cohort was 3 in 27 patients $(11 \%)$. Among patients with nonrupture state, operative mortality was $0 \%$.

\section{Treatment and Course of Penetrating Ulcers}

A total of 53 patients with PAU were studied (Figure 2, $B$ ). Average age at diagnosis was 71.4 years (range, $33-90)$, and $29(55 \%)$ were female (Figure 3, A). The PAU was located in the ascending aorta in 4 patients $(8 \%)$ and in the descending aorta in 49 patients $(92 \%)$ (Figure 3, B). Twenty-five patients (47\%) presented with ulceration surrounded by associated hematoma.

Of the 53 patients, 17 presented with rupture state symptoms (rupture or impending rupture), representing an incidence of rupture at presentation of $32 \%$ compared 

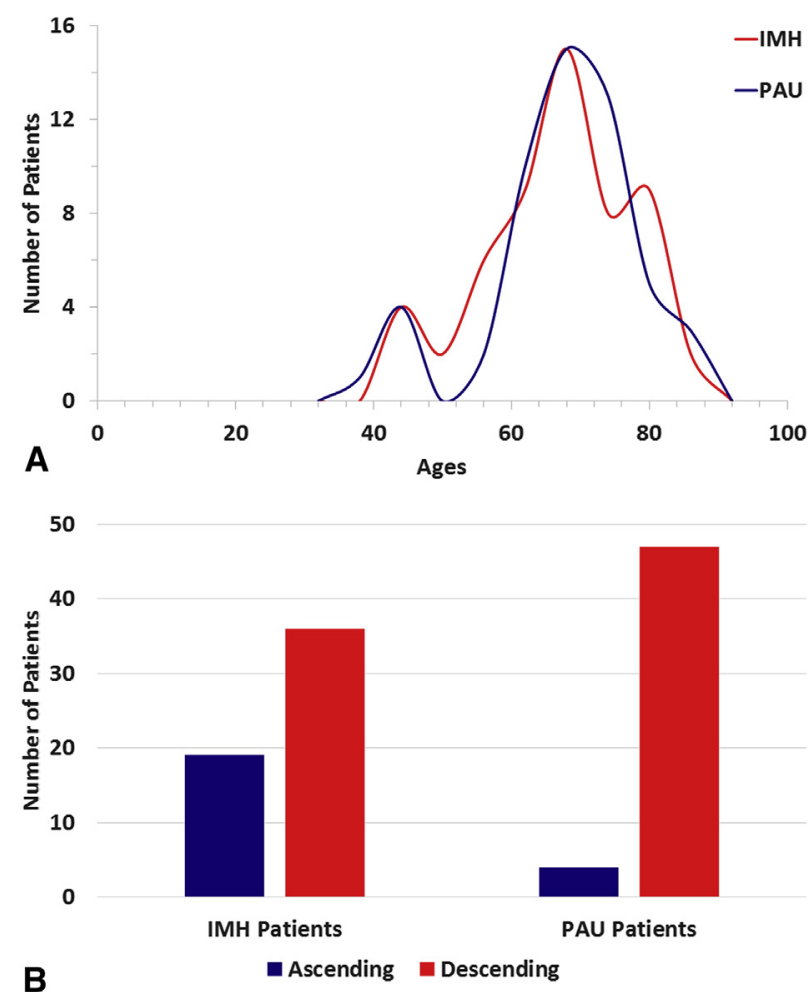

FIGURE 3. Age and lesion location distribution of IMH and PAU cohorts. A, Histogram of presentation age for patients with IMH and PAU. $\mathrm{B}$, Lesion location for IMH and PAU cohorts. IMH, Intramural hematoma; $P A U$, penetrating atherosclerotic ulcer.

with $8 \%$ and $4 \%$ for type $\mathrm{A}$ and $\mathrm{B}$ classic dissection $(P<.001)$. Of those 17 patients, $12(71 \%)$ were treated surgically, and the other $5(29 \%)$ were considered inoperable on the basis of rupture state, age, and other major comorbidities. One patient was noted to have impending rupture and survived to discharge after surgery. In total, of patients who presented with rupture state symptoms, none of the 5 nonsurgical patients survived to discharge, whereas 10 surgical patients $(59 \%)$ survived to discharge. On the basis of severity of symptoms, radiographic images, and comorbidities, the 36 patients $(69 \%)$ with nonrupture state PAU were triaged to initial surgical or initial medical therapy. Eleven patients $(31 \%)$ underwent initial surgical repair, and the remaining 25 patients $(69 \%)$ were treated medically, with follow-up imaging. Late surgical repair was performed on 6 patients. In total, 29 patients underwent operative repair: 24 with surgical aortic graft replacement (details on the extent of surgical graft replacement are provided in Table E1 in the Appendix), 4 with descending endovascular graft, and 1 with aortic thromboexclusion (in the pre-endograft era). No in-hospital deaths or early deaths occurred for patients with nonrupture state.

In total, 46 patients ( $87 \%$ ) survived to first discharge, and postdiagnosis follow-up imaging was available for 32 patients $(70 \%)$. Overall mean imaging follow-up time was 41.3 months (range, 1-151). Of the 25 initially medically treated patients, imaging follow-up was available for $20 \mathrm{pa}-$ tients $(80 \%)$, with a mean imaging time during medical treatment period of 34.3 months (range, 1-92) (Figure 4, C). Three patients (15\%) demonstrated spontaneous resolution of the lesion (mean imaging time, 42.3 months; range, 29-60), and 11 patients (55\%) showed no change in appearance (mean imaging time, 41.0 months; range, 1-64). Six patients $(30 \%)$ showed worsening, with 2 patients $(33 \%)$ demonstrating conversion to flap dissection and 4 patients $(66 \%)$ manifesting expansion of the ulcer and appearance of associated IMH. The mean time to worsening was 18.0 months (range, 1-92). Late operation was performed on all 6 patients who displayed worsening, with mean time to operation of 18.3 months (range, 1-93). All patients who underwent late operation survived to discharge.

A total of 29 patients with PAU underwent operative repair during their overall treatment course, with 27 (93\%) surviving to discharge. Fifteen patients $(56 \%)$ had postsurgical follow-up imaging, with a mean imaging time of 42.9 months (range, 1-125) (Figure 4, D). Thirteen patients (87\%) demonstrated stable aortic appearance (mean imaging time, 46.0 months; range, 3-125). Two patients (13\%) demonstrated postsurgical aortic complications, both with focal dissection contiguous to repaired descending portion of aorta (mean time to complication was 8.1 months; range, 1-16). Total operative mortality for the PAU cohort was 2 in $29(7 \%)$. Among patients with nonrupture state, operative mortality was $0 \%$.

\section{Survival Analysis and Comparison of Treatment Outcomes}

Overall Kaplan-Meier survivals were $77 \%, 70 \%, 58 \%$, and $33 \%$ at $1,3,5$, and 10 years, respectively (Figure $5, A$ ). Long-term survivals for patients with IMH were $75 \%$, $69 \%, 64 \%$, and $39 \%$ at $1,3,5$, and 10 years, respectively. Long-term survivals for patients with PAU were $79 \%$, $72 \%, 51 \%$, and $28 \%$ at $1,3,5$, and 10 years, respectively (Figure $5, B$ ). Mortality rate decreases significantly once the initial phase of rupture state in-hospital deaths is surpassed; half of patients with rupture state died within 1.2 months of presentation. Of 7 surgically treated patients with rupture state IMH, only 3 survived ( $43 \%$ ), whereas of 12 surgically treated patients with rupture state PAU, 10 survived $(82 \%)$. With a 2 -proportion $z$ test, the $P$ value of this difference is .067 . No significant differences were observed for Kaplan-Meier survivals between ascending and descending lesions (for IMH, log-rank $P=.14$ and for PAU, $\log$-rank $P=.55$ ).

Of the 14 early deaths, all but 1 were due to rupture or postrupture repair complications. Death certificates were available for 32 patients, and causes of death are categorized by relation to aortic pathology (Table 3 ). The single 

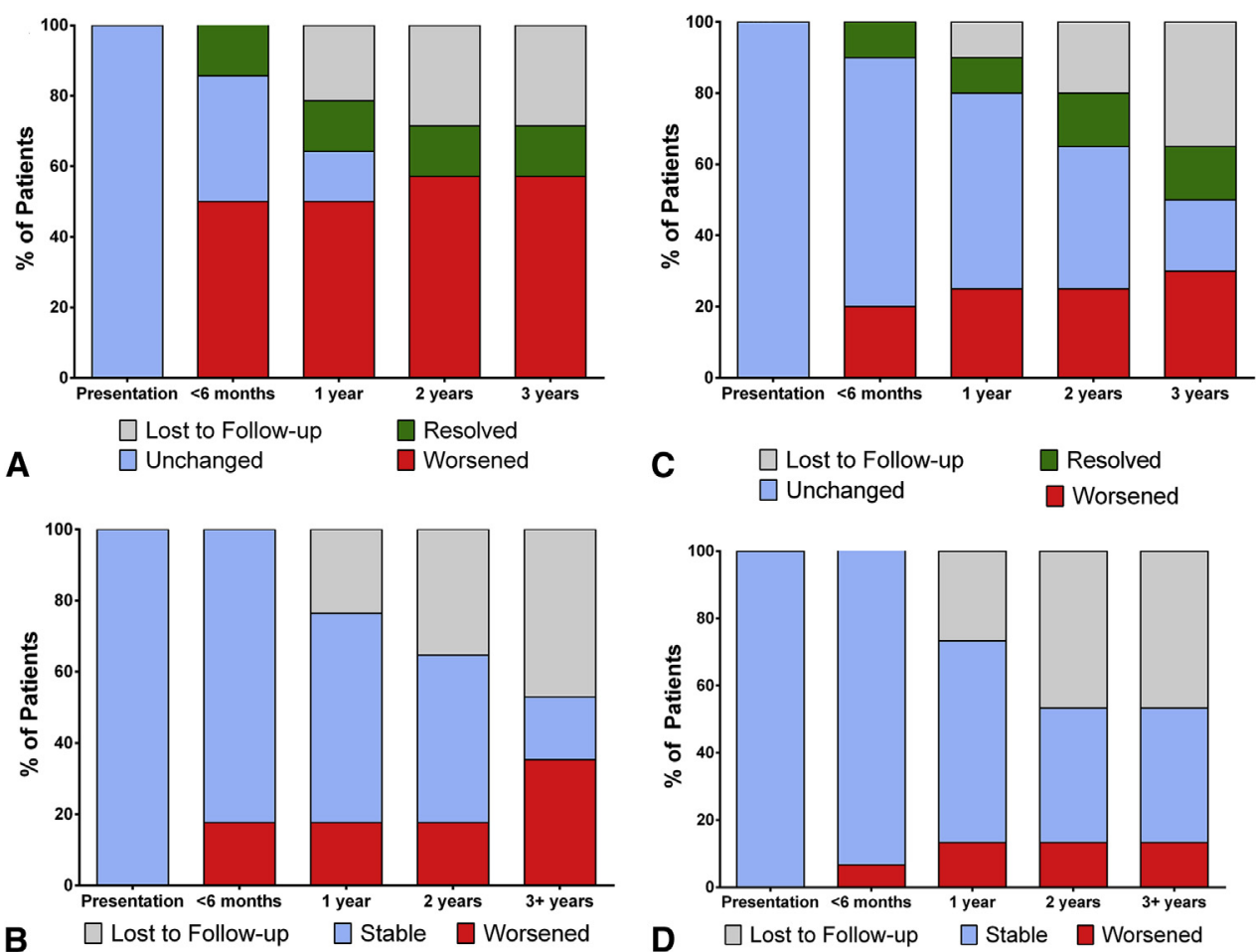

FIGURE 4. Behavior of medically and surgically managed IMH and PAU lesions examined via imaging follow-up. A, Presurgical imaging follow-up for 14 patients with IMH. B, Postsurgical imaging follow-up for 17 patients with IMH. C, Presurgical imaging follow-up for 20 patients with PAU. D, Postsurgical imaging follow-up for 15 patients with PAU.

patient with ascending IMH who was triaged to initial medical treatment had ascending rupture and died.

Late survival of patients under differing treatment groups was compared among patients with nonrupture state. All patients with nonrupture state survived to discharge. Strict comparison is not possible, because this study is retrospective and patients are selected for surgical and medical management on the basis of the relative severity of aortic presentation and comorbidities. Comorbidities and characteristics were similar between nonrupture initial medical and initial surgical groups for both IMH and PAU cohorts (Table 4). History of tobacco use was significantly decreased for patients with PAU who underwent initial surgical treatment compared with those who underwent initial medical treatment, but all other comorbidities and characteristics showed no significant differences.

Patients with IMH undergoing initial surgical treatment appeared to do better than patients treated medically (at least in the first 8 years of follow-up), although this difference was not statistically significant when analyzed by the log-rank test $(P=.10)$. However, analyzing the survival using the Gehan-Breslow-Wilcoxon test, which puts more emphasis on the survival in the earliest deaths of the curve, showed a significant improvement $(P=.028)$. Median survival for initial medical treatment was 6.7 years, and median survival for initial surgical treatment was 11.7 years (Figure 6, A).
In contrast, patients with nonrupture state PAU treated with initial surgical treatment had significantly better survivals than patients treated with initial medical treatment $(P<.05)$. Median survival for initial medical treatment was 4.6 years, whereas patients treated with initial surgical treatment had greater than $50 \%$ survival at 13 years (no median survival is available) (Figure 6, $B$ ).

\section{DISCUSSION}

In recent years, understanding of IMH and PAU has improved because assessment has extended beyond the original hospital admission into midterm follow-up. However, results of these studies have been mixed, and the relative effectiveness of timely medical treatment, open surgical repair, and prophylactic or timely endovascular repair has been unclear.

This study extends our previous 2002 report on the midterm experience with IMH and penetrating ulcer at the Aortic Institute at Yale-New Haven. ${ }^{6}$ The earlier report included a total of 45 patients; in the current study, we expand our patient cohort to 108 patients treated over the course of approximately 20 years, enabling more precise interpretation of imaging follow-up results and comparison of survival outcomes for different treatment regimens. We present our experience with IMH and PAU lesions at our institution. On the basis of our early demonstration of the malignant outlook with these lesions, we have maintained 

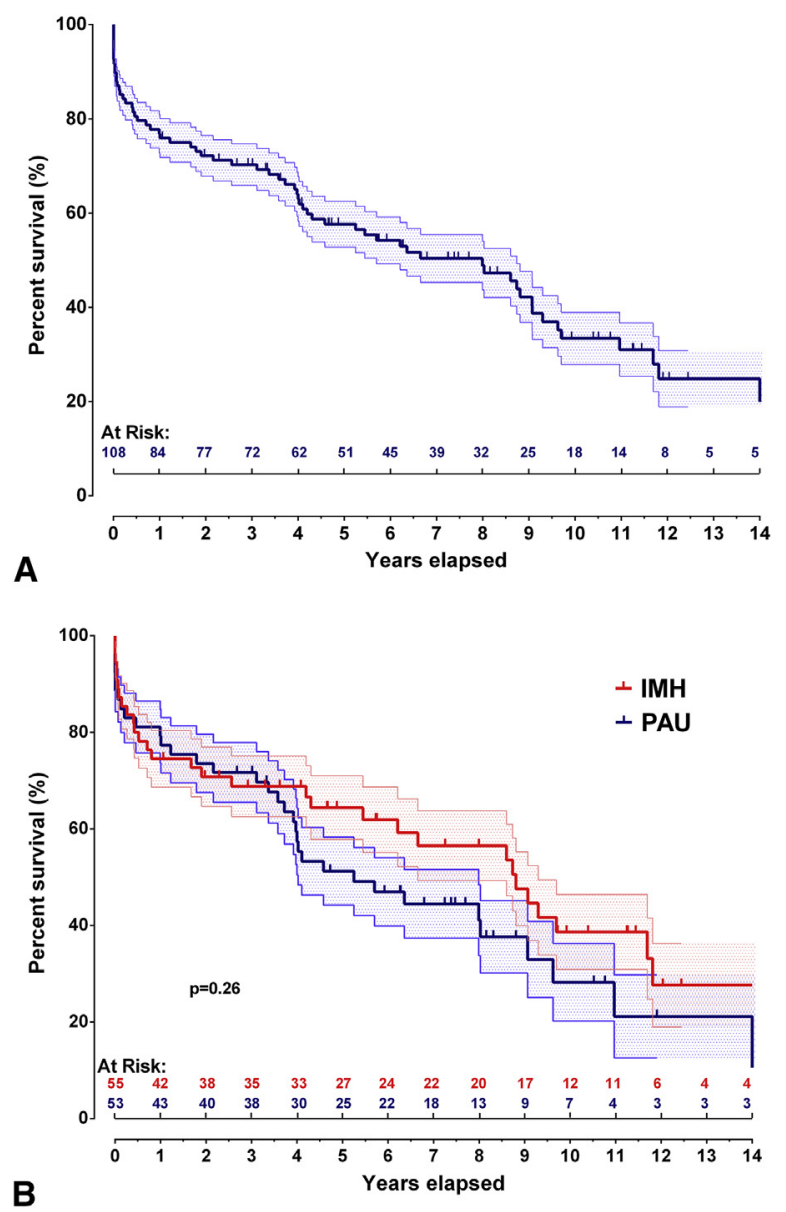

FIGURE 5. A, Kaplan-Meier actuarial survivals for all patients in this study. Shaded areas represent standard errors. B, Kaplan-Meier actuarial survivals for IMH and PAU cohorts. Patients with IMH had slightly better survivals than patients with PAU $(P=.26)$. IMH, Intramural hematoma; $P A U$, penetrating atherosclerotic ulcer.

a low threshold for open surgical repair (and relative caution regarding endovascular stent therapy).

In the present study, we found that the onset of IMH and PAU occurred at a relatively late age, in patients significantly older than those with classic dissection. We also noted that female patients predominated, in contrast to most other cardiovascular and aortic disorders. This female predominance may reflect the increase in female-male proportion in elderly populations. ${ }^{24}$ We documented an increased incidence of atypical aortic branching variants among patients with IMH and PAU compared with healthy populations, especially in those with descending IMH. This reinforces our previous work identifying atypical aortic branching variants as markers of general thoracic aortic disease. $^{23,25}$ In addition, we observed no branch vascular occlusion for IMH or PAU lesions.

Our results demonstrate that an expectant but aggressive approach toward patients with IMH or PAU is reasonable. We maintain a low threshold toward expectant intervention
TABLE 3. Causes of death in patients with intramural hematoma and penetrating atherosclerotic ulcer

\begin{tabular}{ll}
\hline \multicolumn{1}{c}{$\mathbf{I M H}(\mathbf{n}=\mathbf{3 1})$} & \multicolumn{1}{c}{ PAU $(\mathbf{n}=\mathbf{3 4})$} \\
\hline $\begin{array}{l}\text { Early } \\
\text { Rupture (3) }\end{array}$ & Rupture (5) \\
$\begin{array}{l}\text { Postoperative rupture repair } \\
\text { complication (4) }\end{array}$ & $\begin{array}{c}\text { Postoperative rupture repair } \\
\text { complication (2) }\end{array}$ \\
Cardiovascular-related, nonrupture (1) & \\
Late & \\
Aorta-related (4) & Aorta-related (4) \\
Possible aorta-related (3) & Possible aorta-related (5) \\
Nonaortic (10) & Nonaortic (7) \\
Unknown (6) & Unknown (11) \\
\hline$I M H$, Intramural hematoma; $P A U$, penetrating atherosclerotic ulcer.
\end{tabular}

in the case of radiographic worsening or persistent pain, despite medical treatment. Patients demonstrating rupture or impending rupture underwent immediate surgical repair whenever possible. Incidences of rupture state at presentation of IMH and PAU were $18 \%$ and $32 \%$, respectively, significantly elevated compared with rates of rupture of typical aortic dissection (both type A and B). ${ }^{1,6}$ Incidence of rupture at presentation for PAU was substantially greater than classic dissection and IMH, illustrating the especially malignant nature of penetrating ulcer. Although the concept of impending rupture is inherently speculative, the high in-hospital mortality of the patients so classified in this series argues that our radiographic and clinical criteria for "impending rupture" are measuring a real phenomenon. We noted that, among patients with rupture state, the survival of patients who were acutely operated was considerably lower for those with IMH than for those with PAU ( $43 \%$ vs $82 \%, P=.067)$. This may reflect that PAUs represent easier surgical targets, being localized, with intact layers of the aortic wall. Reflecting our low threshold for surgical treatment, $41 \%$ of patients with nonrupture state IMH and $29 \%$ of patients with nonrupture state PAUs underwent initial surgical repair. The majority of ascending lesions underwent operative repair when possible, but significant proportions of descending lesions were also operatively repaired during the first admission.

In our cohort, few patients with IMH and PAU demonstrated resolution over time. Of medically managed patients with IMH and imaging follow-up, 57\% showed aortic worsening on imaging follow-up and $43 \%$ had eventual late operation, all within 1 year of diagnosis. For PAU, the lesion resolved rarely and persisted or worsened in $85 \%$ of cases, with $30 \%$ requiring late operation. In addition, in late follow-up, we observed that $27 \%$ to $42 \%$ of IMH deaths and $25 \%$ to $56 \%$ of PAU deaths were aortic related, again indicating the persistence of the aortic malignancy.

Our survival curves are reflective of our aggressive institutional surgical strategy; these survival curves are 
TABLE 4. Comparison of characteristics and comorbidities of intramural hematoma and penetrating atherosclerotic ulcer by initial treatment

\begin{tabular}{|c|c|c|c|c|c|c|}
\hline \multirow[b]{2}{*}{ Variables } & \multicolumn{3}{|c|}{ IMH } & \multicolumn{3}{|c|}{ PAU } \\
\hline & Initial medical & Initial surgical & $P$ value & Initial medical & Initial surgical & $P$ value \\
\hline No. of patients & 25 & 20 & & 25 & 11 & \\
\hline Mean age at diagnosis $(y)$ & $70.5 \pm 10.8$ & $68.4 \pm 9.79$ & .50 & $70.0 \pm 12.0$ & $70.2 \pm 9.6$ & .96 \\
\hline Female $(\%)$ & $16(64 \%)$ & $12(60 \%)$ & 1.00 & $15(60 \%)$ & $6(55 \%)$ & 1.00 \\
\hline Hypertension & $24(96 \%)$ & $17(85 \%)$ & .31 & $20(80 \%)$ & $11(100 \%)$ & .30 \\
\hline Dyslipidemia & $10(40 \%)$ & $8(40 \%)$ & 1.00 & $13(52 \%)$ & $7(64 \%)$ & .72 \\
\hline Tobacco & $7(28 \%)$ & $5(25 \%)$ & 1.00 & $13(52 \%)$ & $1(9 \%)$ & $.025 *$ \\
\hline Coronary artery disease & $7(28 \%)$ & $3(15 \%)$ & .47 & $10(40 \%)$ & $2(18 \%)$ & .27 \\
\hline Pulmonary disease & $9(36 \%)$ & $3(15 \%)$ & .18 & $10(40 \%)$ & $5(45 \%)$ & 1.00 \\
\hline Renal dysfunction & $4(16 \%)$ & $1(5 \%)$ & .36 & $3(12 \%)$ & $0(0 \%)$ & .54 \\
\hline Aortic branching variant & $10(40 \%)$ & $4(20 \%)$ & .20 & $5(20 \%)$ & $3(27 \%)$ & 68 \\
\hline
\end{tabular}

$I M H$, Intramural hematoma; $P A U$, penetrating atherosclerotic ulcer. *Indicates statistical significance $(P<0.05)$.

not intended to reflect the independent natural history of the disease. Assessments of the progression and natural history of the disease are examined through long-term imaging follow-up of nonoperated patients, whereas survival curves are intended to reflect our institutional treatment superimposed on the natural disease.

Triage of patients into initial medical and initial surgical groups depended on the lesion location and severity of presentation. To avoid additional complexity and to keep groups adequately large for analysis, we did not divide groups in Figure 2 (overall patient flow diagram) into ascending and descending locations. This may have obscured a greater virulence of ascending lesions. Thus, direct comparison of the 2 treatment groups-surgical and medical-does not necessarily reflect alternate treatment options. Survival of initially surgically managed patients with IMH outstripped medically managed patients for the first 8 years of follow-up. This suggests that surgical therapy safely restored survival to equal that of the less sick medical group. Comparison of this proportion with our low surgical mortality reinforces our prior assessment that unless early resolution of IMH occurs, resection should be strongly considered in case of continued aortic enlargement, expansion of the hematoma, or conversion to typical dissection. ${ }^{6}$ We noted a significant advantage in actuarial survival for patients with PAU undergoing initial surgical management compared with initial medical treatment. Our results contrast with those presented by Cho and colleagues, ${ }^{5}$ who reported that patients with PAU treated with surgical treatment had poorer survivals than patients with IMH. PAUs rarely resolve, and the high rupture rate and presence of the lesion make for a poor prognosis compared with more immediate and aggressive surgical repair, especially given the low operative mortality we observe for patients with nonrupture state.

We also noted a number of postsurgical aortic complications in repaired IMH aortas. Of the available patients, $35 \%$ showed some form of worsening on follow-up imaging, including 2 of the 3 patients repaired endovascularly and
2 of the 3 patients repaired with thromboexclusion. Furthermore, 24\% required reoperation to repair endoleak or pseudoaneurysm. This may indicate that IMH is an indicator of severe underlying aortic pathology. Unlike $\mathrm{IMH}$, surgical therapy of PAU appears more durable, without postsurgical progression, likely because of the localized nature of PAU; $87 \%$ of operatively repaired patients with PAU demonstrated stable aortic appearance with mean imaging follow-up of approximately 8 years. The stability of repaired PAUs supports liberal surgical treatment: Medically treated PAUs remain at risk for rupture or complication, but the surgically repaired aortas are free from development of further aortic pathology.

Given the infrequent healing, our minimal in-hospital mortality $(0 \%)$ among patients with nonrupture state, and our reasonable long-term survival in these elderly patients, we believe our aggressive strategy is supported by this study. Of note, our recommendations contrast with many of the studies in Table 1. However, the disparity between Asian and Western clinical experiences with IMH and PAU is well established for both IMH and PAU and for aortic syndromes in general. ${ }^{3,4,26,27}$ Therefore, we present our study as a recommendation for Western centers with acutely presenting patients.

\section{Study Limitations}

This observational study has significant limitations. Although we present a relatively large number of cases in our full available institutional experience over approximately 20 years with complete survival and treatment follow-up, longer imaging follow-up times would be welcomed. This matter is complicated by the lack of compliance in older patients in returning for regular screening, the high rate of surgery in our population that further reduces the proportion returning for imaging of unoperated IMH and PAU, and the advanced age and correspondingly short survival of our patients. Our patients were treated according to a paradigm influenced by our prior experience, prior analyses for publications, and 

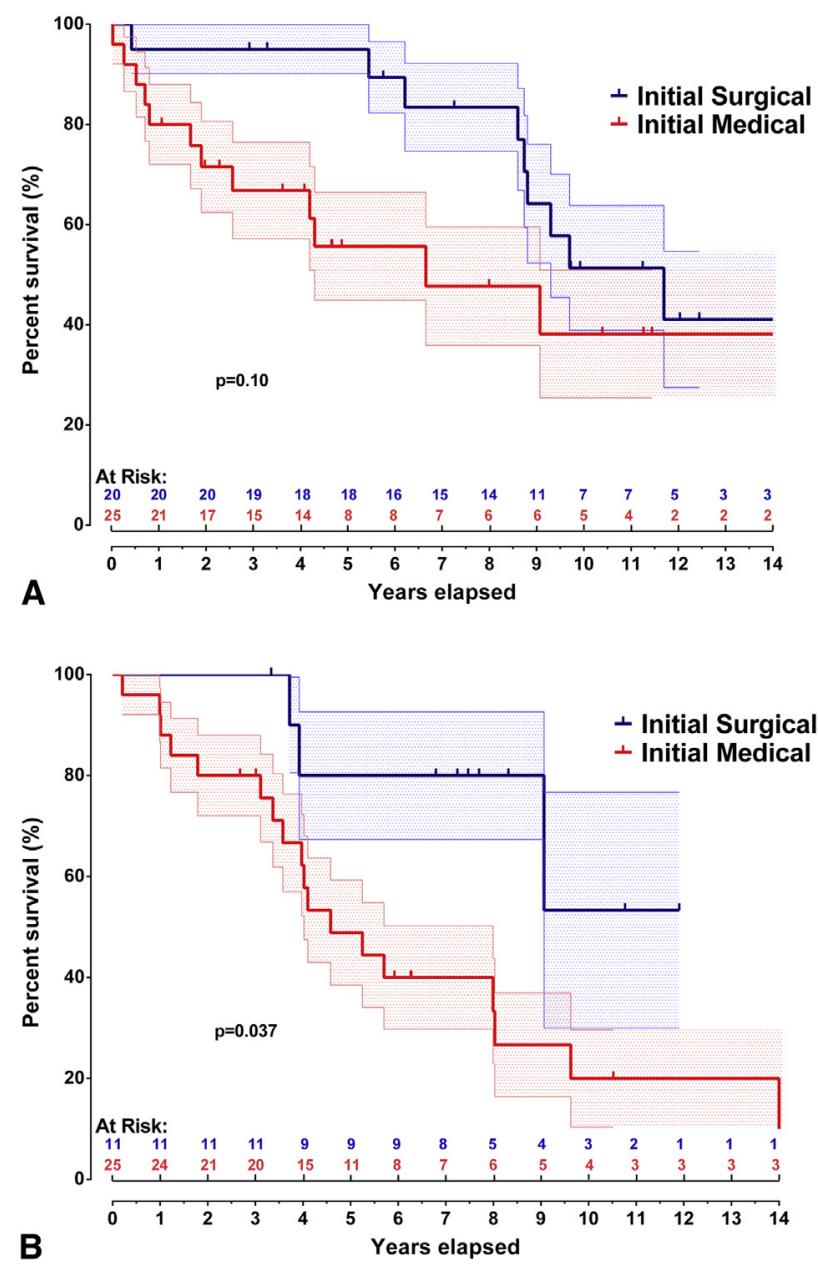

FIGURE 6. A, Kaplan-Meier actuarial survivals, with shaded areas representing standard errors, for patients with nonrupture state IMH comparing survival between initial surgical and initial medical cohorts $(P=.10)$. B, Kaplan-Meier actuarial survivals, with shaded areas representing standard errors, for patients with nonrupture state PAU comparing survival between initial surgical and initial medical cohorts $(P=.037)$.

clinical preferences. Because of the early inception of this study and our institutional bias toward durable open therapy of aortic lesions, we report scant application of endovascular therapies (TEVAR in 3 patients with IMH and 4 patients with PAU), although we do think that the localized nature of PAUs may render them suitable for coverage by stent grafts. In the current era, however, we are using endovascular techniques considerably more often than represented in this experience, which goes back considerably in time, to permit longer follow-up of these interesting lesions, IMH and PAU.

\section{CONCLUSIONS}

Our findings and recommendations, based on this experience with the IMH and PAU variant forms of acute aortic dissection, are summarized as follows:
1. IMH and PAU are diseases of the elderly and occur more commonly in female patients.

2. IMH and PAU both have substantially higher rupture rates on initial presentation than the classic (flap) form of aortic dissection.

3. No branch vascular occlusion occurred for any IMH or PAU cases in this cohort.

4. True healing of IMH or PAU is rare, with worsening and late surgery common. IMH resulted in more longitudinally widespread aortic degeneration than PAU, both before surgical and endovascular repair and afterward. Frequent and mandatory follow-up imaging is extremely important to rule out clinical or radiographic worsening and prevent late rupture.

5. An open surgical approach was safe in both the urgent early setting and the later time period for both PAU and IMH. No operative deaths occurred for patients in the nonrupture state group.

6. Our approach of a low threshold for intervention in case of impending rupture or radiographic worsening yielded low in-hospital mortality and satisfactory long-term survival.

7. An even more aggressive approach toward surgical repair may be warranted, given the relatively frequent radiographic progress and need for late surgery and the infrequency of true healing of both IMH and PAU.

\section{Conflict of Interest Statement}

Dr Rizzo reports consulting fees from CTI-CRO. Dr Elefteriades reports consulting fees from Jarvik Heart, DSMB and equity ownership in Coolspine. All other authors have nothing to disclose with regard to commercial support.

You can watch a Webcast of this AATS meeting presentation by going to: http://webcast.aats.org/2015/Video/ Tuesday/04-28-15_612_1655_Chou.mp4.

\section{References}

1. Coady MA, Rizzo JA, Elefteriades JA. Pathologic variants of thoracic aortic dissections. Penetrating atherosclerotic ulcers and intramural hematomas. Cardiol Clin. 1999;17:637-57.

2. Coady MA, Ikonomidis JS, Cheung AT, Matsumoto AH, Dake MD, Chaikof EL, et al. Surgical management of descending thoracic aortic disease: open and endovascular approaches: a scientific statement from the American Heart Association. Circulation. 2010;121:2780-804.

3. Clough RE, Nienaber CA. Management of acute aortic syndrome. Nat Rev Cardiol. 2015;12:103-14

4. Lansman SL, Saunders PC, Malekan R, Spielvogel D. Acute aortic syndrome. J Thorac Cardiovasc Surg. 2010;140:S92-7; discussion S142-6.

5. Cho KR, Stanson AW, Potter DD, Cherry KJ, Schaff HV, Sundt TM III Penetrating atherosclerotic ulcer of the descending thoracic aorta and arch. J Thorac Cardiovasc Surg. 2004;127:1393-401.

6. Tittle SL, Lynch RJ, Cole PE, Singh HS, Rizzo JA, Kopf GS, et al. Midterm follow-up of penetrating ulcer and intramural hematoma of the aorta. $J$ Thorac Cardiovasc Surg. 2002;123:1051-9.

7. Moizumi Y, Komatsu T, Motoyoshi N, Tabayashi K. Clinical features and longterm outcome of type A and type B intramural hematoma of the aorta. J Thorac Cardiovasc Surg. 2004;127:421-7. 
8. Kaji S, Akasaka T, Katayama M, Yamamuro A, Yamabe K, Tamita K, et al. Long-term prognosis of patients with type B aortic intramural hematoma Circulation. 2003;108(Suppl 1):Ii307-11.

9. Evangelista A, Mukherjee D, Mehta RH, O'Gara PT, Fattori R, Cooper JV, et al Acute intramural hematoma of the aorta: a mystery in evolution. Circulation. 2005:111:1063-70.

10. Kitai T, Kaji S, Yamamuro A, Tani T, Tamita K, Kinoshita M, et al. Clinical outcomes of medical therapy and timely operation in initially diagnosed type a aortic intramural hematoma: a 20-year experience. Circulation. 2009;120: S292-8.

11. Shimokawa T, Ozawa N, Takanashi S, Itoh $\mathrm{T}$. Intermediate-term results of surgical treatment of acute intramural hematoma involving the ascending aorta. Ann Thorac Surg. 2008;85:982-6.

12. Song JK, Yim JH, Ahn JM, Kim DH, Kang JW, Lee TY, et al. Outcomes of patients with acute type a aortic intramural hematoma. Circulation. 2009;120: 2046-52.

13. Sawaki S, Hirate Y, Ashida S, Takanohashi A, Yagami K, Usui M. Clinical outcomes of medical treatment of acute type A intramural hematoma. Asian Cardiovasc Thorac Ann. 2010;18:354-9.

14. Tolenaar JL, Harris KM, Upchurch GR Jr, Evangelista A, Moll FL, di Eusanio M, et al. The differences and similarities between intramural hematoma of the descending aorta and acute type B dissection. J Vasc Surg. 2013;58:1498-504.

15. Nathan DP, William B, Lai E, Wang GJ, Desai N, Woo EY, et al. Presentation, complications, and natural history of penetrating atherosclerotic ulcer disease. J Vasc Surg. 2012;55:10-5.

16. Sundt TM. Intramural hematoma and penetrating atherosclerotic ulcer of the aorta. Ann Thorac Surg. 2007;83:S835-41; discussion S46-50.

17. Estrera AL, Sandhu HK, Leake SS, Charlton-Ouw KM, Afifi RO, Miller CC III, et al. Early and late outcomes of acute type A aortic dissection with intramural hematoma. J Thorac Cardiovasc Surg. 2015;149:137-42.

18. Choi YJ, Son JW, Lee SH, Kim U, Shin DG, Kim YJ, et al. Treatment patterns and their outcomes of acute aortic intramural hematoma in real world: multicenter registry for aortic intramural hematoma. BMC Cardiovasc Disord. 2014; $14: 103$.

19. Robbins RC, McManus RP, Mitchell RS, Latter DR, Moon MR, Olinger GN, et al. Management of patients with intramural hematoma of the thoracic aorta. Circulation. 1993;88:II1-10.

20. Hiratzka LF, Bakris GL, Beckman JA, Bersin RM, Carr VF, Casey DE Jr, et al. 2010 ACCF/AHA/AATS/ACR/ASA/SCA/SCAI/SIR/STS/SVM Guidelines for the diagnosis and management of patients with thoracic aortic disease. A Report of the American College of Cardiology Foundation/American Heart Association Task Force on Practice Guidelines, American Association for Thoracic Surgery, American College of Radiology, American Stroke Association, Society of Cardiovascular Anesthesiologists, Society for Cardiovascular Angiography and Interventions, Society of Interventional Radiology, Society of Thoracic Surgeons, and Society for Vascular Medicine. J Am Coll Cardiol. 2010;55: e27-129.

21. Rizzo JA, Chen J, Fang H, Ziganshin BA, Elefteriades JA. Statistical challenges in identifying risk factors for aortic disease. AORTA. 2014;2:45-55.

22. Hagan PG, Nienaber CA, Isselbacher EM, Bruckman D, Karavite DJ, Russman PL, et al. The International Registry of Acute Aortic Dissection (IRAD): new insights into an old disease. JAMA. 2000;283:897-903.

23. Dumfarth J, Chou AS, Ziganshin BA, Bhandari R, Peterss S, Tranquilli M, et al. Atypical aortic arch branching variants: a novel marker for thoracic aortic disease. J Thorac Cardiovasc Surg. 2015;149:1586-92.

24. Ortman JM, Velkoff VA, Hogan H. An aging nation: the older population in the United States. Current Population Reports, P25-1140. U.S. Census Bureau, Washington, DC. 2014. Available at: http://www.census.gov/prod/2014pubs/ p25-1140.pdf. Accessed July 29, 2015.

25. Hornick M, Moomiaie R, Mojibian H, Ziganshin B, Almuwaqqat Z, Lee ES, et al. 'Bovine' aortic arch - a marker for thoracic aortic disease. Cardiology. 2012;123: 116-24.

26. Elefteriades JA, Ziganshin BA. Examining the face of aortic dissection outside the Western world. J Thorac Cardiovasc Surg. 2014;148:3001-2.

27. Wang W, Duan W, Xue Y, Wang L, Liu J, Yu S, et al. Clinical features of acute aortic dissection from the Registry of Aortic Dissection in China. J Thorac Cardiovasc Surg. 2014;148:2995-3000.

Key Words: intramural hematoma, long-term follow-up, penetrating atherosclerotic ulcer

\section{Discussion}

Dr K. Minatoya (Osaka, Japan). Actually, my first question was already answered in the slides. So I would like to raise a big issue regarding IMH. Asian country surgeons doubt the concept of IMH, and the Japanese guidelines stopped using the term IMH because we think the term is a pathologic concept, and I don't believe the IMH situation basically, and I think it is just a thrombosed classic dissection.

In your article, the mortality of emergency operation in a patient with IMH is more than $50 \%$, which is rather higher rate, and in my understanding, surgical results of the thrombosed type acute classic dissection usually show better mortality rate among the open classic dissection. What do you think is the reason? What is the big difference between the IMH and the thrombosed type to lead the different mortality?

Dr Ziganshin. We think the difference between classic dissection and IMHs in our cohort is related to the fact that most of the procedures performed on an emergency basis were in patients from the rupture state group. To be frank, $80 \%$ of all patients from the rupture state group had an actual rupture, so they presented to us in the most acute and severe condition. We believe that is what contributed most to the significant mortality of that cohort.

Dr Minatoya. Did all patients with IMH on initial presentation have any symptoms? According to the Japanese guidelines, aortic diameter less than $50 \mathrm{~mm}$, and the false lumen than $10 \mathrm{~mm}$ with an ulcer-like projection, I mean, a thrombosed type could be followed medically safely, and we believe that in clinical practice. So what is your indication for surgery in a patient with IMH?

Dr Ziganshin. Our general approach toward IMHs is the following: for a type $\mathrm{A}$, an ascending $\mathrm{IMH}$, we would proceed to surgery on admission during the initial hospitalization. If the patient presents with an IMH of the descending aorta, we would use the approach that you suggest, a more expectant one: we would conduct medical management initially and proceed to surgery at a later stage.

I think that is the slight difference between the Western approach and the Asian approach toward treatment of IMHs. We found our patients to be more acute, and we were slightly more aggressive toward ascending IMHs.

Dr Minatoya. In your article, IMH and PAU both had a substantially higher rupture rate on initial presentation, as you said, than the classic form of aortic dissection. Do you have some speculation of the reason?

Dr Ziganshin. We are not sure why this is the case. One of the reasons might be because we are a large referral center, and we get a lot of patients from other hospitals transferred to us with ruptures or impending rupture conditions. Also, when we reported our previous experience on the midterm follow-up of IMHs and penetrating ulcers in 2002, we showed an even higher rupture rate of $46 \%$ for these lesions. 
So it seems that over the course of the time, the rupture rates decreased slightly. The rupture rates found in our study are $18 \%$ for the IMH cohort and $32 \%$ for the PAU cohort. These are similar to rupture rates that we found in the Asian literature, the Western reports, and the International Registry of Acute Aortic Dissection database.

Dr A. Estrera (Houston, Tex). You outlined your treatment algorithm for IMH very well. At Yale University, what about those patients who present with PAU who are not ruptured. How do you manage those patients?

Dr Ziganshin. I think the approach toward PAUs is slightly less aggressive now. We tend to observe them more initially for both ascending and descending locations. However, we have to say that in our cohort of 108 patients, we had only 4 patients with a penetrating ulcer in the ascending aorta, and 3 of those patients underwent surgery. The remaining patients who had a penetrating ulcer in the descending aorta were managed expectantly unless they presented with rupture.

Dr Estrera. Is there a size criteria? How do you decide when to intervene, and is there an expectant management protocol?

Dr Ziganshin. It is not so much the size as the dynamics of the lesion on follow-up imaging. If we visualize a resolution or a stable lesion, we continue initial medical management. If we see worsening in the form of progression to classic aortic dissection, as the most severe case, or if the penetrating ulcer, for example, develops an associated IMH, or if the penetrating ulcer deepens in size and enlarges, we will proceed with surgical treatment. So it is not so much related to the aortic size as to the appearance of the penetrating ulcers in follow-up.

In terms of the IMHs, these are similar criteria. We watch them on serial scans, and if worsening occurs, we observe a dissection, we observe worsening in terms of the increase in size of the hematoma itself or an appearance of an associated penetrating ulcer, in these situations we also proceed with surgical management.

Dr H. Ogino (Tokyo, Japan). My question is similar to Dr Minatoya's. There is a lot of discussion about the difference between the IMH and the thrombosed dissection. Are there any differences of the historical examination between the classic dissection and IMH in your series? Because as someone reported, the incidence of rupture is higher in the IMH compared with the classic open dissection. Would you make a comment?

Dr Ziganshin. Could you please repeat the first question? Is there any difference in terms of histology?

Dr Ogino. Yes. Someone reported the dissection occurs in the more outside layer in the IMH. Did you find a similar thing?

Dr Ziganshin. Well, in this particular study, we included only patients who strictly met the criteria for being classified as an IMH with crescentic thickening in the aortic wall. Unfortunately, analysis of the histology was beyond the scope of the current study, and we did not do a comparison between classic dissection and IMH/PAU lesions for the purposes of this study.

But, again, we think the high rupture rates are not unusual. They have been reported by many centers, and some of the studies I showed in the presentation report similar rupture rates on presentation. Some centers report even higher rupture rates for IMHs and penetrating ulcers. However, I do not believe that we included anyone in our study who had a thrombosed dissection because all of these patients presented to us acutely. They were with us from day 1 of the initial presentation. We are confident that all of these patients had real IMHs.

Dr B. Yang (Ann Arbor, Mich). A question about your cohort. You didn't divide patients into type A or type B IMH or penetrating ulcer. You just discussed the type A aortic penetrating ulcer. You did 3 cases on an emergency basis, and you didn't operate in 1 case. How about IMH? How many of your acute type A IMHs went to surgery, and how many did you observe, and why did you observe those patients? What's your treatment for acute type A IMH, open repair, or TEVAR to cover the primary tear at the proximal descending?

Dr Ziganshin. For the IMHs, all of the patients who had a type A IMH were triaged to surgical management. The issue here is that some patients were deemed unfit for surgery because of their advanced age and comorbidities or they did not elect to undergo surgery. Therefore, those patients did not undergo operation, and they are included in the medical management cohort, for example, of the rupture state cases, and thus showed poor survival.

If the IMH is located in the descending aorta, we use an expectant approach. For the majority of our patients, we tend to perform more open procedures than endovascular procedures, primarily because this study spans all the way back to 1995, to the pre-endovascular era, and because of the specifics of our center as well. However, more recently, a few of our patients with descending IMHs underwent an endovascular procedure.

To follow up on that point, a few patients in the pre-endovascular era also underwent a thromboexclusion procedure, and, of course, now we no longer perform that procedure because that's not necessitated by the availability of endovascular techniques.

Dr Yang. Did you perform any TEVAR for any type A IMH?

Dr Ziganshin. No, we did not.

Dr Yang. For retrograde type A IMH, we did several cases with TEVAR to cover the primary intimal tear at the proximal descending aorta. Actually, the IMH in the ascending aorta resolved nicely in the 3 to 6 months after TEVAR just to cover the primary tear in the proximal descending, and the ascending aortic wall healed nicely.

Dr Ziganshin. That is very interesting. 
TABLE E1. Extent of aortic graft replacement in patients with intramural hematoma $(n=26)$ and penetrating atherosclerotic ulcer $(n=24)$ undergoing open surgical repair

\begin{tabular}{lllr}
\hline Lesion type & \multicolumn{1}{c}{ Lesion location } & Extent of open aortic graft replacement & No. of procedures \\
\hline IMH & Ascending/arch & Ascending + hemi arch (all under DHCA) & 16 \\
& Descending/thoracoabdominal & Descending & 5 \\
& & Descending and upper abdominal & 5 \\
PAU & Ascending/arch & Ascending + total arch (DHCA) & 1 \\
& & Total arch (DHCA) & 1 \\
& Descending/thoracoabdominal & Distal arch and descending & 4 \\
& & Descending & 12 \\
& & Descending and upper abdominal & 6
\end{tabular}

$\overline{D H C A}$, Deep hypothermic circulatory arrest; $I M H$, intramural hematoma; $P A U$, penetrating atherosclerotic ulcer. 